\title{
Prediction of inflows into Lake Kariba using a combination of physical and empirical models
}

\author{
Shepherd Muchuru \\ Department of Geography, Geoinformatics and Meteorology, University of Pretoria, Pretoria, South Africa \\ Willem A. Landman \\ Council for Scientific and Industrial Research, Natural Resources and the Environment, and Department of Geography, Geoinformatics and \\ Meteorology, University of Pretoria, Pretoria, South Africa
}

David G. DeWitt

International Research Institute for Climate and Society, Lamont-Doherty Earth Observatory of Columbia University, Palisades, NY, USA

Corresponding Author: Muchuru Shepherd

Email Address: shephido@yahoo.com

Contact Number: +27837857115

Postal address: University of Pretoria, Private bag X20 Hatfield, Pretoria 0028

\begin{abstract}
Seasonal climate forecasts are operationally produced at various climate prediction centres around the world. However, these forecasts may not necessarily be objectively integrated into application models in order to help with decision-making processes. The use of hydro- meteorological models may be proven effective for reservoir operations since accurate and reliable prediction of reservoir inflows can provide balanced solution to the problems faced by dam or reservoir managers. This study investigates the use of a combination of physical and empirical models to predict seasonal inflows into Lake Kariba in southern Africa. Two predictions systems are considered. The first uses antecedent seasonal rainfall totals over the upper Zambezi catchment as predictor in a statistical model for estimating seasonal inflows into Lake Kariba. The second and more sophisticated method uses predicted low-level atmospheric circulation of a coupled ocean-atmosphere general circulation model (CGCM) downscaled to the inflows. Forecast verification results are presented for five run-on 3-month seasons; from September to June over an independent hindcast period of 14 years (1995/6 to 2008/9). Verification is conducted using the relative operating characteristic (ROC) and the reliability diagram. In addition to the presented verification statistics, the hindcasts are also evaluated in terms of their economic value as a usefulness indicator of forecast quality for bureaucrats and to the general public. The models in general perform best during the austral mid-summer season of DJF (seasonal onset of inflows) and the autumn season of MAM (main inflow season). Moreover, the prediction system that uses the output of the CGCM is superior to the simple statistical approach. An additional forecast of a recent flooding event (2010/11), which lies outside of the 14-year verification window, is presented to further demonstrate the forecast system's operational capability during a season of high inflows that caused societal and infrastructure problems over the region.
\end{abstract}

Key Words: Lake Kariba, seasonal flows; downscaling; verification; water resource management

\section{Introduction}

River flows are sensitive to climatic variability and change. Rainfall and runoff are key drivers of reservoir inflow and vary considerably from year to year making prediction of inflows essential for effective water resource management (Ghosh et al., 2010). Reservoir operation is a multi-complex system which involves designing and operating to make informed decision on when and how much water to accommodate and release 
over time (Stedinger et al., 2001). Improved and reliable flow forecasts can reduce detrimental effects of floods, droughts and water supply for various users (Skotner et al., 2007; Cloke et al., 2009). Over the past years, dam managers often use traditional methods to guide and manage reservoir operation (Refsgaar et al., 1996). The traditional systems of predicting stream flow has its own shortcomings for example, they are not very reliable for balancing the demands from different users. However, the increase in the better understanding of atmospheric processes has resulted in the use and advancement of seasonal forecasts (Makarau and Jury, 1997). Reliable predictions of inflows in advance can improve the management of water resources systems. The ability to predict future climate fluctuations one or more seasons in advance would have measurable benefits for decision making, also in hydrology (Barnston et al., 2004; Schaake et al., 2010; Thielen et al., 2008; Schaake et al., 2007b).

Rainfall especially in the upper Zambezi catchment is the main driver of the inflows into Lake Kariba. The flow in the river results for the most part from rainfall over the upper catchment. There is a about a one-season delay between the main rainfall month (January) as measured at the inflow gauging station and the maximum inflows (March to May) as measured at the same station (Figure 1). Since rainfall is the main driver for inflows into Lake Kariba, we have previously investigated the prediction of 3-month seasonal rainfall totals over the Kariba catchment and found good skill (Muchuru et al., 2014). Currently, there is in place a one-month look-ahead forecast model being used at Lake Kariba (ZRA, 2005). This forecast model is based on the Index-variable method for flows at Victoria Falls in the upper catchment of the Lake. The lead time between water arriving at the top of Victoria Falls and the water arriving at the Lake's inflow gauging system is approximately two weeks. Two-week lead time might not be adequate enough to effectively predict the flows at Victoria Falls and subsequently estimating inflows into the Lake. This lead-time is particularly crucial during the main inflow months of March and April when the largest flows from the upper catchment arrive. Moreover, the occurrence of exceptionally high flow volumes over the lower catchment tend to depend upon flows from the upper catchment reaching that area. Introducing a comprehensive set of model forecasts over a long lead-time might therefore be useful. The use of a longer lead-time can effectively reduce the risk of a possible underestimation of the flows into Kariba, particularly during high flow periods. For example, one of the biggest floods that occurred in the Zambezi basin was in 2010/2011 during the austral mid-summer. Lake Kariba reservoir was almost at full capacity when intense and prolonged rainfall over large areas of the basin originated a very big flood into Kariba. The enormous flood wave downstream resulted in loss of life and property. Extreme floods have also resulted in considerable loss of life, social disruptions, and extensive economic damage.
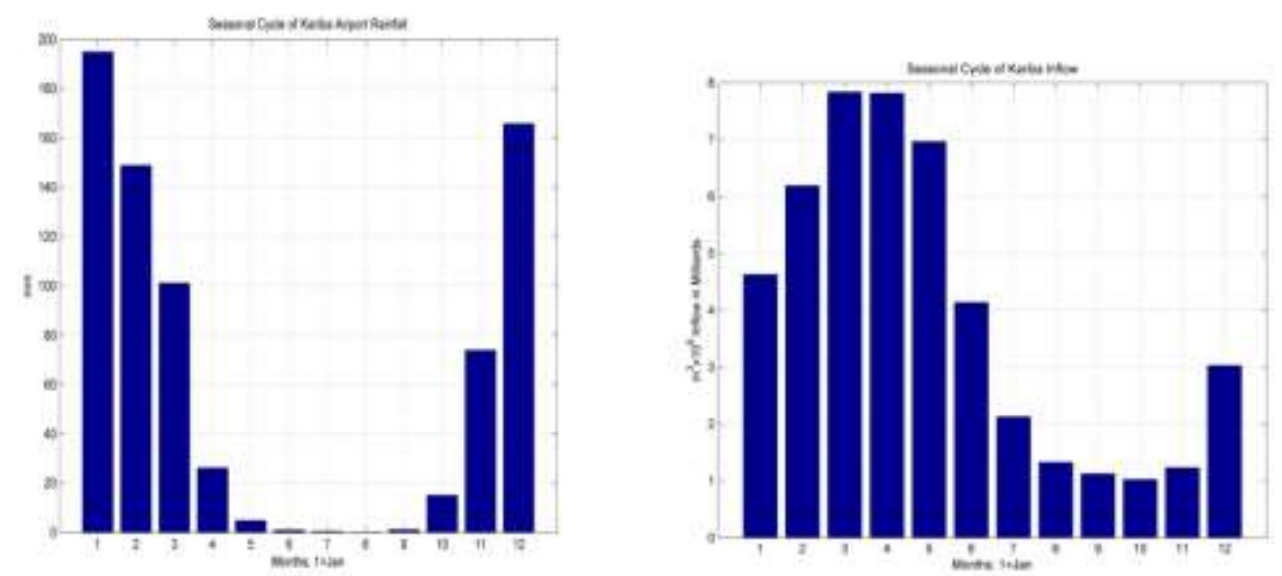

Figure1. The sesonal cycles of the Kariba rainfall (left panel) and the inflow (right panel. Rainfall data was acquired from the Zambezi River authority.

The main reason for objectively predicting inflows is to better ascertain the uncertainty about the future and the need to reduce unforeseen catastrophes (Krzysztofowicz, 2001). The increase in the understanding of atmospheric processes has harnessed to improve the accuracy and reliability of forecasts for all climatic and 
hydrological variables (precipitation, temperature and runoff) (Cane et al., 1994; Hastenrath et al., 1995; Landman and Goddard, 2002). Forecasts still remain far from perfect, and may fall short of reaching society's expectations for timely and reliable warnings. Therefore, the need arises to improve prediction system by, for example, through combing physical and empirical models (Goetz et al., 2011; Ziervogel et al., 2005; Lessmann et al., 2012). Several studies of empirical modelling have been carried out to predict stream-flow (OpitzStapleton et al., 2007; Barnston et al., 1999; Tisseuil et al., 2010; Krzysztofowicz., 1999; Goetz et al., 2011; Maier et al., 2000); however most of these approaches still have short-comings to skilfully predict the flows. Therefore, the most common modelling approach is to use the combination of both physical and empirical techniques (Hansen, 2002). A reliable model should use both atmospheric and empirical prediction system, for both atmospheric and hydrologic predictions (Tong et al., 2012) in order to quantify and propagate uncertainty from various sources in the forecasting system. In general, this study will employ approaches to predicting inflow using both observed and predicted climate information. The prediction system will use both physical and empirical models with careful consideration of climatic predictors (Partington et al., 2012; Marco et al., 2010). Forecasts from ocean-atmosphere general circulation models GCMs will be used to translate seasonal forecasts into inflow forecasts using empirical downscaling approaches (Lazenby et al., 2014; Tong et al., 2012).

The study aims to potentially improve the overall management of water resources for Lake Kariba by supplying long-lead forecasts for the likelihood of high or low inflows into the dam to occur. In addition, the prediction system will provide key information on flood risk seasons to different stakeholders for example, hydropower production and water uses (Hamlet et al., 2002). However, forecasting can be performed deterministically or probabilistically ( $\mathrm{Yu}$ et al., 2007). A deterministic forecast identifies a variable to be forecasted, while a probabilistic forecast specifies a probability distribution function pertaining to the predictand (Yu et al., 2007). Probabilistic forecasts can provide risk-based tools for flood alerts and watches, and can be used by dam managers in decision making (Krzysztofowicz., 2001; Stam et al., 1998; Yu et al., 2007; Krzysztofowicz, 1999). Dam managers are mainly concerned about keeping water levels between a Minimum Operating Level (MOL) and a Full Supply Level (FSL). However, this information might not be sufficient to optimize dam management. Probabilistic forecasts can reduce errors of potential misperception of responsibilities and decision making by reservoir operators (Krzysztofowicz, 2001). Since reservoirs have become the most important facilities for distributing water (Ncube et al., 2011), among various purposes, their management is crucial (Wei and Hsu, 2005 and Mujumdar et al., 2010). The inflow into Lake Kariba is mainly influenced by rainfall especially in the upper catchment of the Zambezi River Basin (Balek, 1971). Climate variations have an important impact on water supply in the southern Africa region (Rouault et al., 2003). Population increase and demand for water in southern Africa necessitates effective water management (Chidanti-Malunga, 2011). The need for forecast guidance for an approaching season has thus become necessary. Since the understanding of the predictability of the atmosphere at seasonal-to-interannual time-scales has improved considerably over southern Africa during the past decade (Landman, 2014), the provision of such forecasts has become a possibility (Carson, 1998; Palmer and Anderson, 1993). This notion will be tested here.

\section{Study Area}

Lake Kariba was built in the late 1950's mainly to provide water for hydro-power production. The Lake boasts a reservoir surface area of $5580 \mathrm{~km}^{2}$, a reservoir length of $280 \mathrm{~km}$ and width of $32 \mathrm{~km}$ at its widest point at full supply level. Lake Kariba's upper and lower catchment areas drain from the five riparian states of Angola, Namibia, Botswana, Zambia and Zimbabwe. This drainage area covers some $815000 \mathrm{~km}^{2}$, or $60 \%$ of the whole Zambezi River basin area (Tumbare, 2000). Lake Kariba regulates runoff from an upstream catchment area of $687,535 \mathrm{~km}^{2}$, which is about $50 \%$ of the total Zambezi catchment area. Lake Kariba is operated by both the Governments of the Republics of Zambia and Zimbabwe. Both authorities monitor, operate and maintain the Kariba Dam wall and manage the hydrology of Lake Kariba for hydropower generation and other stakeholder uses. 
Average annual rainfall for the Lake Kariba catchment (see Figure 2) is about 1,000 mm, producing a mean annual discharge of $37,249 \mathrm{~mm}^{3}$ (an average flow rate of $1,181 \mathrm{~m}^{3} / \mathrm{s}$ ). Approximately $50 \%$ of the annual rainfall over the catchment, on average, contributes to the Zambezi base flow (Sharma and Nyumbu 1985). During drought years, the magnitude and duration of average peak flows may be reduced by $70 \%$ or more. Runoff varies considerably from year to year $\left(0.40\right.$ coefficient of variation, from a remarkable $72,800 \mathrm{~mm}^{3}$ in $1957 / 58$ to as low as $12,300 \mathrm{~mm}^{3}$ in 1995/96). The time series of annual flows reveals long-term cycles of high, medium, and low runoff. These cycles also influence runoff efficiency; a sequence of particularly low rainfall years in the catchment, such as the one occurred during the early 1900s and again during the period 1980-1998, can significantly reduce the proportion of annual rainfall that occurs as runoff.

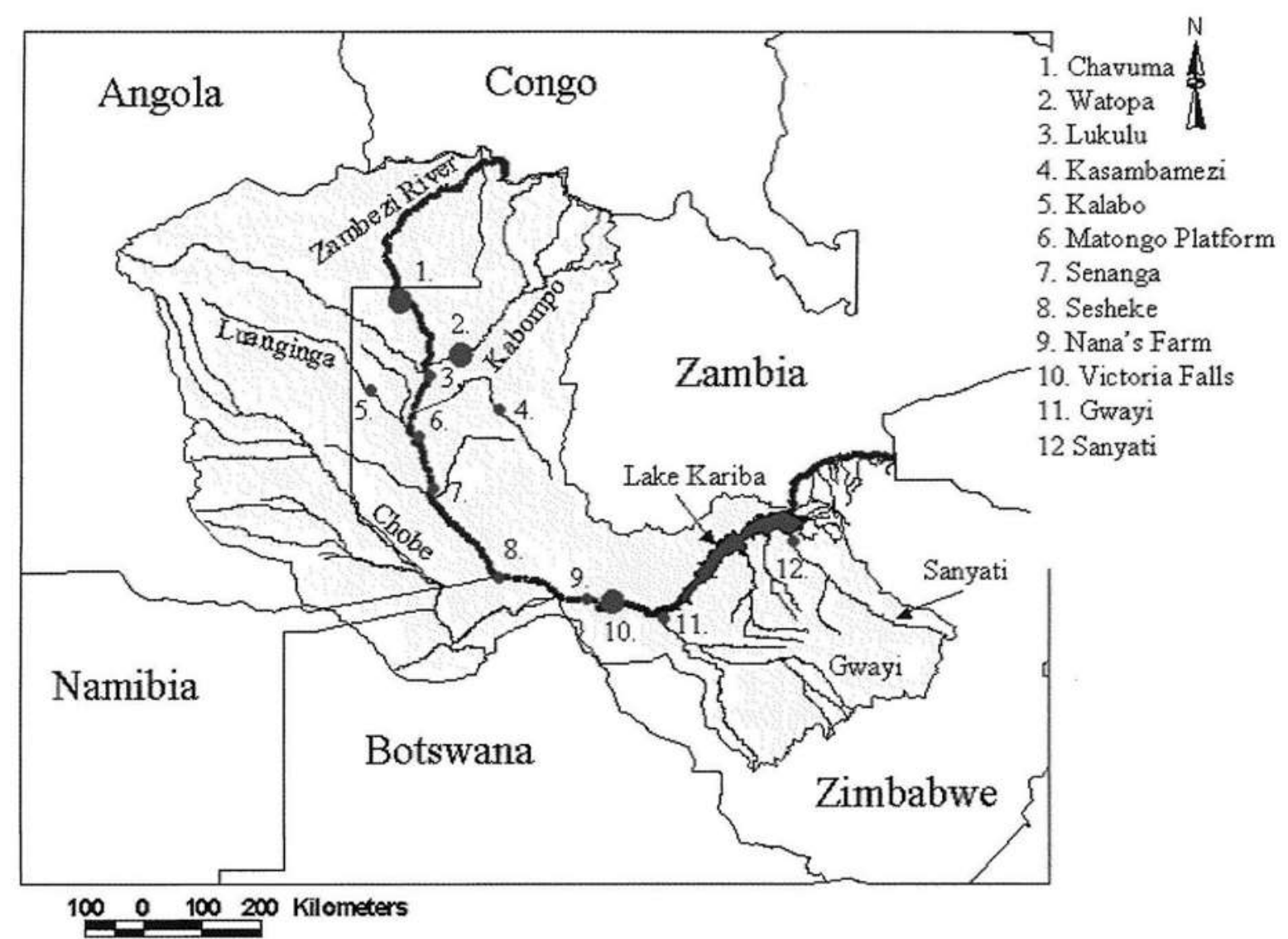

Figure 2. Lake Kariba catchment area (Source: Tumbare, 2000)

3. Data

\subsection{Rainfall data}

The total seasonal rainfall over the upper Zambezi catchment is used as the predictors in a statistical model for estimating inflows into Lake Kariba. The rainfall data used for downscaling and verification is the University of East Anglia's (UEA) Climate Research Unit (CRU) version TS3.1 seasonal precipitation data at a $0.5^{\circ} \mathrm{x} 0.5^{\circ}$ resolution (Harris et al., 2013). Here, the CRU data from only 1982/83 to 2010/11are used. The CRU data represent one of the most comprehensive observational data sets available and have been used in former studies over southern Africa (e.g. Landman and Beraki, 2012). 


\subsection{ECHAM4.5-MOM3 coupled ocean-atmosphere model data}

Statistical downscaling of the archived output of a state-of-the-art coupled ocean-atmosphere general circulation model (CGCM) is the second modelling system considered here for predicting inflows (the first system being the one using upper catchment rainfall as predictor). The CGCM's archived hindcast data used in this study were obtained from the data library of the International Research Institute for Climate and Society (IRI), (DeWitt, 2005). Only five forecast lead-times from the IRI's data library are to be considered. The forecasts for the coupled model are produced near the beginning of the month.

The atmospheric model used is the ECHAM4.5- an atmospheric general circulation model (GCM). The model uses spherical harmonics with a truncation at wavenumber 42 (T42) in the standard version (Roeckner et al., 1996), i.e. a mesh width of $2.8^{\circ}$. The Ocean Model, directly coupled, is version 3 of the Modular Ocean Model (MOM3; Pacanowski and Griffies, 1998). The ocean-atmosphere model used in this research is therefore the ECHAM4.5-MOM3 (DeWitt, 2005) and hindcast data for this fully coupled forecasting system are available from 1982 until July 2012.

\section{Methodology}

\subsection{Statistical downscaling}

Statistical downscaling, a procedure used as early as the 1970's for weather prediction (Glahn and Lowry, 1972), may also be used to assess local climate change impacts (e.g. Wilby et al., 2002) and for climate variability impacts (e.g. Landman and Goddard, 2002). Downscaling translates large-scale model output to a finer resolution (Muluye, 2011) or to a point of interest. The process involves deriving empirical relationships that transform large scale features of the GCM (predictors) to regional scale variables (predictands) such as precipitation (Mujumdar et al., 2008) and in this study, inflows into the Lake. The hindcasts of the coupled model at an approximate $2.8^{\circ} \times 2.8^{\circ}$ resolution are downscaled statistically to the inflow at a gauging station at the inlet of the Lake for the selected seasons of SON through AMJ. The statistical downscaling procedure of model output statistics (MOS; Wilks, 2011) is used here. This procedure can minimize systematic errors of the coupled model (Wilks, 2011; Robertson et al., 2012) since the MOS equations are developed directly in the regression equations ((Landman et al., 2012; Landman and Beraki, 2012; Landman and Goddard, 2002) and can thus reduce model errors in all stages of model development (Wilks, 2011). Moreover, the downscaled forecast should be able to enhance integrated simulation of the applicable variable, in this case inflows, in decisionmaking systems for effective reservoir operation (Braga et al., 2013). In fact, the forecast system proposed here could potentially be of great value to a dam manager of reservoir operations and may be able to reduce risks in dam management decisions. In addition to this forecast system, antecedent rainfall totals over the upper Zambezi catchment are used as inflow predictors in a base-line model against which the more sophisticated forecast system is to be compared.

Since a major driver of seasonal-to-interannual flows in the Zambezi river is the associated rainfall observed over the catchment, a model forecast of the expected rainfall outcomes over the months ahead may aid in the predictions of flows downstream. However, large-scale circulation is more accurately produced by global climate models than rainfall and so circulation should be considered instead in the MOS system for seasonal inflow downscaling (Landman et al., 2012; Landman and Beraki, 2012; Landman and Goddard, 2002). Moreover, it has already been shown that predicted atmospheric circulation can successfully be used to downscale to seasonal rainfall totals over the catchment (Muchuru et al., 2014). The 12-member ensemble mean geopotential height fields at the $850 \mathrm{hPa}$ level are used as predictors in order to obtain the downscaled flow forecasts. Atmospheric circulation at this atmospheric level could be considered as low-level circulation since the area of interest is near the $850 \mathrm{hPa}$ geopotential level. The software to do the statistical downscaling is the Climate Predictability Tool (CPT) of the International Research Institute for Climate and Society (IRI; http://iri.columbia.edu). The procedure to create downscaled hindcasts follows Landman et al., (2012) and includes a number of steps from transforming the Zambezi flows at the inlet of Lake Kariba into an approximate 
normal distribution, prefiltering the predictors ( $850 \mathrm{hPa}$ heights of the CGCM) through empirical orthogonal functions (EOFs) and subsequently producing downscaled inflow data using principal component regression (e.g. Malherbe et al., 2014). The model domain selected from which the downscaling is performed cover the area from Equator to $30^{\circ} \mathrm{S}$, and from Greenwich to $50^{\circ} \mathrm{E}$. MOS equations are first trained over 13 years from 1982-1994, followed by increasing the training period by one year. This incremental increase of the training period mimics an operational forecast setting. The resulting 14-year period for verification and comparison is from $1995 / 96$ to $2008 / 09$.

\subsection{Verification}

Forecasts produced by physical models are liable to systematic errors (Ebert et al., 2000) and may be exaggerated (Lazenby et al., 2014). The errors could be emanating from the initial conditions, errors in the prediction of atmospheric flow (dynamics), and inadequacies in the large-scale and convective rainfall parameterizations. Forecast verification can help to quantify these errors (Brown et al., 2010), to better understand the sources of predictive error and skill and to improve the model performance in order to make better forecast (Mesinger, 1996). In this study only extreme season inflows are considered. Extremes are here defined by the $75^{\text {th }}$ (high inflow category) and $25^{\text {th }}$ (low inflow category) percentile values of the climatological record. The reason to use extreme season thresholds is because a reservoir manager at Lake Kariba may be more interested in the prediction of extreme inflows that are more likely to affect the water level of the dam than "normal" rainfall seasons would (Sene, 2009). Moreover, the prediction of seasonal climate extremes over southern Africa has skill (Landman et al., 2005; Landman et al., 2012; Lazenby et al., 2014). Here we will attempt to test the predictability of extreme inflows into the Lake so that such forecasts may potentially be able to feed into decision support systems that can be used by reservoir managers at the Lake.

For seasonal time scales especially, probabilistic forecasts (i.e. the likelihood of a particular flow outcome to occur) are preferred over deterministic forecasts (e.g. the inflow will be high this coming season) since deterministic forecasts can be misinterpreted if they are portrayed as the only possible future outcome. Moreover, probability forecasts are in fact required in order to enable users to make optimal decisions since predicted uncertainty is a key element in the decision-making process (Troccoli et al., 2008). This notion has also been adopted in water resource management since a reservoir manager needs information available on the likelihood of a coming season to be associated with extreme rainfall totals over the catchment that may lead to high flow volumes into the dam. Reservoir managers may want to also know the reliability with which such probabilistic forecasts are made when they attempt to discriminate high inflow seasons from the rest of the seasons and very low inflow seasons from the rest. Therefore, discrimination and reliability are two attributes of interest here for probabilistic forecasts. Discrimination and reliability are tested using forecast verification measures of the Relative Operating Characteristics (ROC; Mason and Graham, 2002) and the reliability diagram (Hamill, 1997).

\section{Results}

The two forecast systems' - respectively using upper Zambezi rainfall and CGCM low-level circulation as predictors - discrimination and reliability are assessed next by first considering ROC scores over various leadtimes and 3-month seasons and then assessing reliability. Five forecast lead-times are considered and are defined by the number of months between forecast issuance and the first month of the season being forecast. For example, a 1-month lead-time forecast for DJF inflows are for forecasts issued in early November, a 2-month lead-time with forecasts issued in early October, etc. Furthermore, using upper Zambezi rainfall as predictor, a 1-month lead-time forecast would be for rainfall totals over the 3-month season of ASO since this season's totals can only be obtained near the beginning of November. For the CGCM, 1-month lead-time forecasts are those initialised near the beginning of November. 


\subsection{Inflow hindcasts}

Relative operating characteristic (ROC) scores can demonstrate a forecast system's ability to discriminate high (or low) flow events from non-events. Here we are interested in extreme seasons as defined by the seasonal inflows greater than the $75^{\text {th }}$ percentile of the climatological record (high inflows) or less than the $25^{\text {th }}$ percentile (low inflows) of the climatological record. Perfect discrimination is found when the ROC score is 1.0, but no skill forecasts are associated with scores $\leq 0.5$. The ROC score in this study are shown in Figure 3 for both modelling systems, for five lead-times and for eight run-on 3-month seasons.
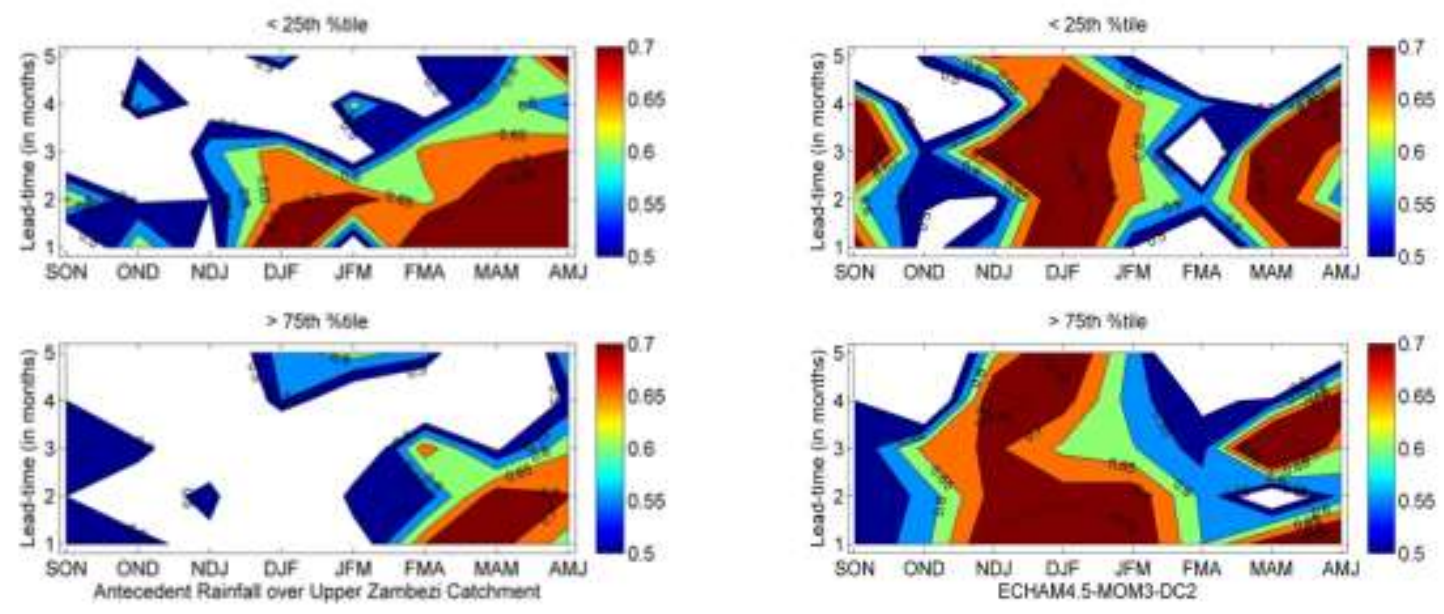

Figure.3. ROC scores of both the CGCM (right panel) and antecedent seasonal rainfall over the upper Zambezi catchment (left panel) obtained by retroactively generated probabilistic hindcasts for low inflow seasons (top panel; less than the 25 th percentile values of the climatological record) and high inflow seasons (bottom panel; greater than the75th percentile of the climatological record) over 14yr (1995/96-2008/09). The x-axes show the 3-monthseasons for which the inflow forecasts are made, and the y-axes shows the five lead-times in months. Scores below 0.5 are shaded white.

The ROC scores in Figure 3 are for the 3-month inflow seasons from SON through AMJ when using respectively the CGCM output (right panels) and the antecedent rainfall over the upper Zambezi catchment (left panels) as inflow predictors. These eight run-on seasons sufficiently cover the main inflow period as shown in Figure 1. The ROC scores are calculated from retroactively generated hindcasts of extremely high and low seasonal inflows. The better discrimination is obtained when using CGCM output as predictors since more seasons and more lead-times are associated with ROC scores higher than 0.5. Moreover, although both prediction systems produce high ROC scores during the main inflow period (c.f. Figure 1) it is only the CGCM that enables the prediction of seasonal inflow onset (i.e. DJF inflow predictions) across all lead-times and for both inflow categories. This relatively high skill associated with DJF may be attributed to the finding that some CGCMs are best at predicting the DJF circulation over southern Africa that is related to the rainfall variability over the region (Landman et al., 2012). High skill DJF onset predictions for inflows should also help with decisions Lake Kariba managers need to make at the start of the main inflow time of the year. However, such managers certainly also want to know well ahead of time what to expect during the main inflow season of MAM (Figure 1). During this time, the reservoir starts to get most of its inflow from rivers and tributaries. High ROC scores are indeed found for both predictions systems for MAM, but the scores are somewhat lower than for DJF and also only high for shorter lead-times. Notwithstanding, for both the onset and for the main inflow period, ROC scores suggest useable forecast discrimination may be possible at lead-times far exceeding the 2-week lead time as described in the Standard Operating Procedure (SOP) manual (ZRA, 2005). Therefore, these skill levels and their associated lead-times presented here provide evidence that a decision support tool for reservoir managers, in order to make informed decisions regarding the likelihood of high or low rain-fed inflows into the reservoir during several months ahead of time, may well be feasible. 
ROC scores' measure of forecast performance is sometimes questionable due to its insensitivity to reliability (Troccoli et al., 2008). Therefore, it is imperative to assess the confidence with which the probabilistic forecasts of extremely high or low seasonal flows are made. Only the DJF and MAM seasons are considered from now on since they are for both forecast systems (CGCM output and the antecedent rainfall over the upper Zambezi catchment) associated with the highest ROC scores. Figure 4 (a, b) shows the 1- to -3month lead reliability plots and frequency histograms for DJF and for MAM, as well as for both forecast systems. For perfect reliability (the forecast probabilities exactly match the observed frequencies of respectively high and low seasonal flows) the weighted least squares regression lines of the reliability curves (not shown for the sake of clarity) will occur on top of the thick diagonal line. When the slope of a regression line is shallower (steeper) than the diagonal lines of perfect reliability, forecasts for a particular category are said be over- (under-) confident. DJF 1- and 2-month lead-time verification of the CGCM (the thin solid and dashed lines and lines with asterisks of Figure $4 \mathrm{a}$, left panel) shows under-confidence for both categories since these regression lines are for the most part steeper than the diagonal line of perfect reliability. On the other hand, 3-month lead-time forecasts for DJF as produced by the CGCM (solid and dashed lines with plus signs) show under-confidence because these lines are found to be shallower than the diagonal. For MAM inflows predicted by the CGCM reliability is lower than found for DJF since the regression lines are further removed from perfect reliability. Even lower reliability is found for using antecedent rainfall as predictor (Figure $4 \mathrm{~b}$ ). Figures $4 \mathrm{a}$ and $\mathrm{b}$ show in general that the probability hindcasts of the DJF season seem more reliable than the MAM season, and using the CGCM output to downscale to the inflows are superior to using antecedent seasonal rainfall as predictor of the flows. The same result is found for the ROC scores. One may ask then why did rainfall totals over the upper catchment not turn out to be as skilful predictor of the flows as opposed to using predicted atmospheric circulation. One likely explanation is that, especially for DJF inflows, is that by the time DJF inflows are predicted with the simple statistical approach (at best, observed rainfall up to October is used as predictor) not much rain has actually fallen over the catchment (to drive the flows) as seen by the annual rainfall cycle depicted in Figure 1. However, short lead-time (1 to 2 months) forecasts using rainfall as predictor did perform reasonable well for MAM inflows (Figure 3). 
a) DJF Kariba Inflow; ECHAM-MOM MAM Kariba Inflow, ECHAM-MOM

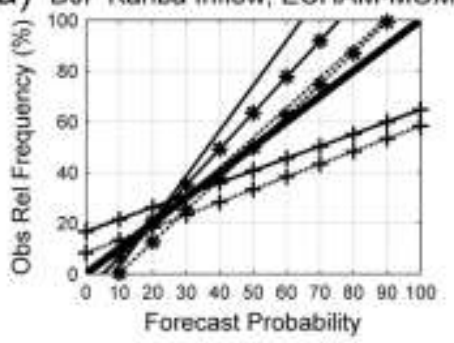

1995/96 - 2008/09
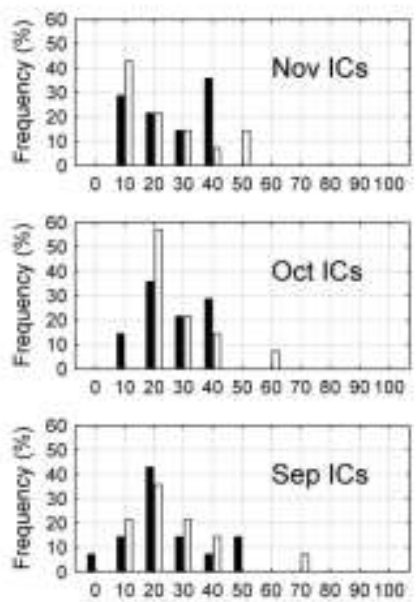

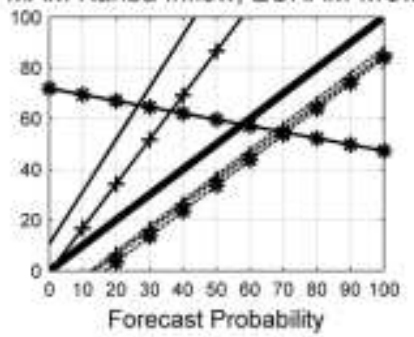

1996 - 2009
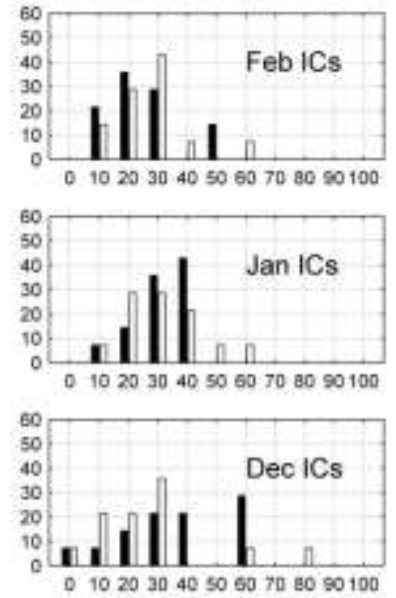


\section{b) DJF Kariba Inflow; Upper Zambezi MAM Kariba Inflow; Upper Zambezi}
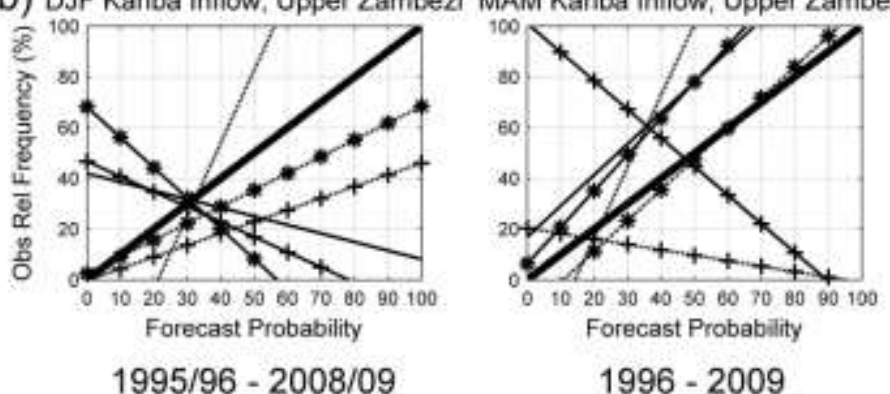

1995/96 - 2008/09

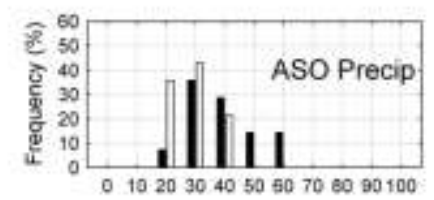

$1996-2009$
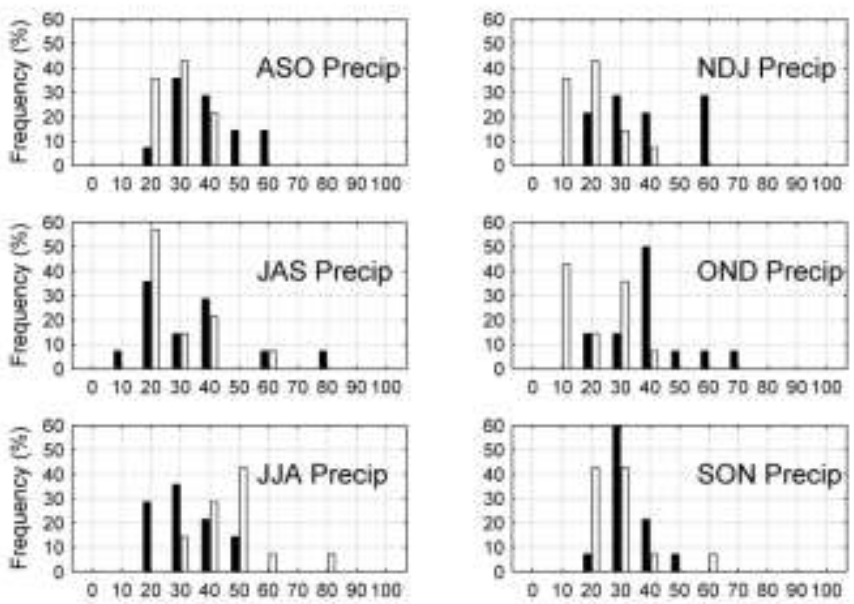

Figure 4. Reliability diagrams (top panels) and frequency histograms for above- $(>75$ th percentile) and below- $(<25$ th percentile) normal DJF (left panels) and MAM (right panels) 1- to 3-month lead-time forecasts produced by a) downscaling the $850 \mathrm{hPa}$ geopotential heights of the ECHAM4.5-MOM3-DC2 coupled model to inflows into Lake Kariba, and by Figure b) using the antecedent seasonal rainfall totals over the upper Zambezi catchment as predictors of Lake Kariba inflows. The thick black line of the reliability diagrams represents perfect reliability of the forecasts, while the rest of the lines represent weighted least-squares regression lines of reliability: Solid and dashed lines respectively represent the above- and below-normal categories for 1-month lead-times; solid and dashed lines with asterisks are for 2-month lead-times; solid and dashed lines with plus signs are for 3-month lead-times. For the frequency histograms the black bars represent abovenormal flows and the white bars represent below-normal flows. Also shown on the frequency histograms are the Figure 4 a) initialization month and Figure 4b) the rainfall season used as predictor.

\subsection{Value of the probabilistic inflow forecasts}

Reservoir managers, who are also decision makers, are largely interested in both profit making and value for money (Hagedorn et al., 2008) as well as optimized reservoir operations (Alemu et al., 2011). In the past, such managers may have mostly been presented with technical verification parameters describing the skill of probabilistic forecast systems (e.g. Hagedorn et al., 2008) through scoring metrics such as the Brier skill score (Hagedorn et al., 2008; Wilks, 2011) and those presented above. However, in addition to be presented with measures of skill such forecast users may in fact want to know whether or not spending a high amount of capital on forecasts from a forecast system that is reliable is indeed leading to higher profits or return of investment as opposed to not using any forecast information. Richardson (2000), Roulston et al. (2003) and Muluye (2011) assessed forecast systems on a simple optimal decision-making, cost-loss analysis technique. Here we similarly attempt to evaluate both our forecast systems in terms of the economic gain they promise to a user (Hagedorn and Smith 2009) as expressed through effective interest rates. These rates are typically calculated over a relatively long period of time spanning several years. Here the economic value of Kariba inflow forecasts are assessed over the same $14 \mathrm{yr}$ verification period described above. 
Effective interest rates are positive when the investment made in the forecasts have produced positive outcomes, while negative values suggest that money may have been lost by the investors during the evaluation period. The effective interest rate values presented in Figure 5 show positive values during spring (SON), mid-summer (DJF) and autumn (MAM) when the CGCM output is used as predictor (top panel), but is only positive from the JFM season onwards for the case of using antecedent seasonal rainfall as predictors (bottom panel). These results are in strong agreement with the ROC graphs of Figure 3 and show that seasons associated with high skill over the catchment are likely to be those associated with the best chance of financial gain (e.g. Muchuru et al., 2014). Both the ROC scores (Figure 3) and the rates of Figure 4 similarly suggest that inflows predicted by the output of the CGCM may have the best chance for the Kariba Lake manager to gain the most financially. Owing to the strong association with the ROC scores, effective interest rates may be considered as a useroriented verification parameter to communicate the value of probability forecasts to a wider user community.
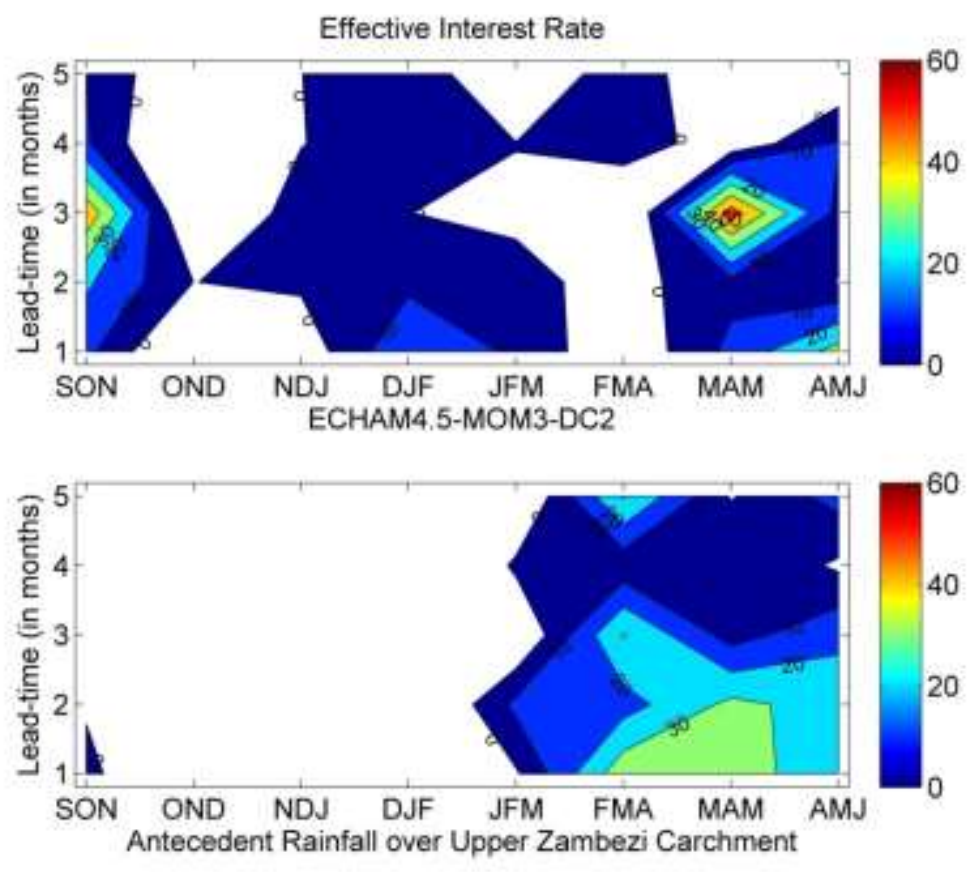

Figure 5. Effective interest rates associated with the CGCM (top panel) and with the antecedent rainfall over upper Zambezi catchment as predictor (bottom panel) from SON to AMJ.

An additional approach to communicate forecast value may be achieved through the so-called two-alternative forced choice test (2AFC; Mason and Weigel, 2009). The 2AFC is a scoring procedure that is generic to be usable on forecasts ranging from simple yes-no forecasts of dichotomous outcomes, to forecasts of continuous variables. 2AFC scores have broad intuitive appeal in that the expected score of an unskilled set of forecasts (random guessing or perpetually identical forecasts) is $50 \%$, and is interpretable as an indication of how often the forecasts are correct, even when the forecasts are expressed probabilistically and/or the observations are not discrete. Figure $6 \mathrm{a}$ and $\mathrm{b}$, shows the $2 \mathrm{AFC}$ scores for both forecast systems and as was the case for the effective interest rates, the graphs show strong similarities to the ROC scores of Figure 3.

To summarise the results, ROC scores suggest skilful forecasts to be possible during onset and during the main inflow seasons. Moreover, the better modelling approach is to use the atmospheric circulation from the CGCM as predictor. In general, the same conclusions regarding best season and best practice are also found when assessing the economic value of forecasts and when demonstrating forecast quality to the general public (2AFC scores). 

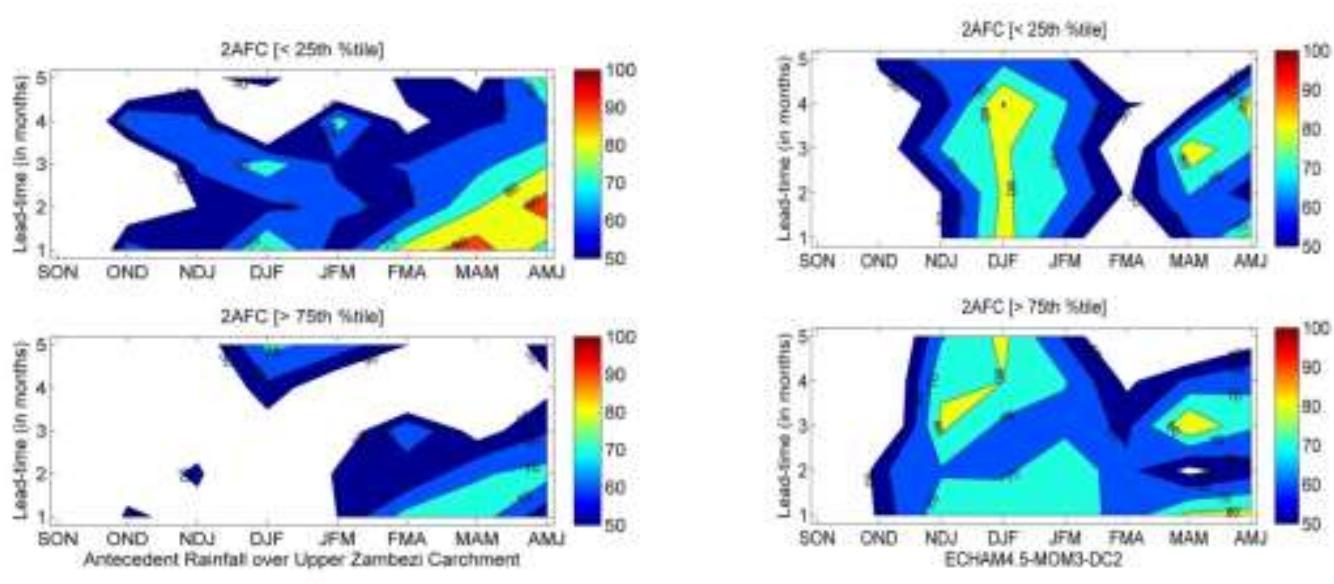

Figure 6 a and b. 2AFC Scores associated with the antecedent rainfall over upper Zambezi catchment as predictor and the CGCM.

\subsection{Year-by-year hindcasts}

The above sections have demonstrated the various skill levels of the forecasting systems presented here. The verification work, both from a scientific and from a forecast user's perspective, resulted in the following conclusions being drawn. Antecedent seasonal rainfall over the upper Zambezi catchment is not as skilful in predicting inflows into the Lake as opposed to using as predictor the coupled ocean-atmosphere's model output of low-level atmospheric circulation; the 3-month seasons of highest inflow predictability is DJF and MAM; and although MAM is the peak inflow season, its associated forecast skill levels are inferior to DJF inflow forecast skill. To provide a statement that may be best interpreted by a user of these forecasts is that we have demonstrated our ability to predict for the seasonal onset and peak seasonal inflows into Lake Kariba by using output of a state-of-the-art climate model, although more modest skill levels are associated with the peak inflows.

In this section we will show and discuss some of the actual downscaled hindcasts, season by season, over the 14-year verification period for DJF and for MAM. The value in presenting these hindcasts could provide information regarding the prediction of particular seasons of high and low inflows, the potential value of probabilistic over deterministic forecasts, and also to provide independent forecasts that may be assimilated into decision support systems. Both probabilistic and deterministic inflow forecasts are presented. The former forecasts show the likelihood of inflows being below (above) the $25^{\text {th }}\left(75^{\text {th }}\right)$ percentile of the climatological record, while the latter shows a forecast by inflow volumes $\left(\mathrm{m}^{3} \times 10^{9}\right)$ and forecast limits as defined by the 1 standard deviation of the forecasts. Figure $7 \mathrm{a}$ and $\mathrm{b}$ shows only the 1-month lead forecasts for DJF and the 3month lead forecasts for MAM since good verification skills have been found for these lead-times and that with such lead-times decisions regarding optimal dam management and operations can be made before the end of the calendar year preceding the main inflow period.

The DJF (Figure 7a) high probability forecasts for high (low) inflows are usually associated with La Niña (El Niño) years. For example, the five highest probability forecasts for high inflows are associated with the La Niña seasons of 1995/96, 1998/99, 1999/2000, 2005/06 and 2007/08, while the four highest probability forecast years for low inflows during the 1997/98, 2002/03, 2004/5 and 2006/07 are associated with El Niño years. So the forecasts seem to be responding to ENSO years, as has been found to be the case for DJF rainfall predictions over the region (Landman and Beraki, 2012; Landman et al., 2012). Moreover, this ENSO link is also seen for the most part in the observed inflows where the five highest observed inflow years of 1996/97, 1998/99, 2000/01, 2005/06 and 2007/08 are associated with La Niña years. Also, some of the lowest inflow years are on the other hand found during the El Niño years of 1997/98, 2002/03, 2004/05 and 2006/07.

For the MAM forecasts presented in Figure $7 \mathrm{~b}$ there is a good agreement between some of the high-probability forecast seasons (for both high and low volume inflows) and the deterministic estimates. For example, with 
increased seasonal flows towards 1999 and 2000, from 2002 to 2004, and from 2005 towards 2009, the forecast probabilities increased in accordance with the deterministic forecast ranges. Regarding the observed and predicted flows and their association with ENSO, this link seem to be weaker as was found for DJF - low inflows during the 1996 La Niña and high inflows during the 2007 El Niño.

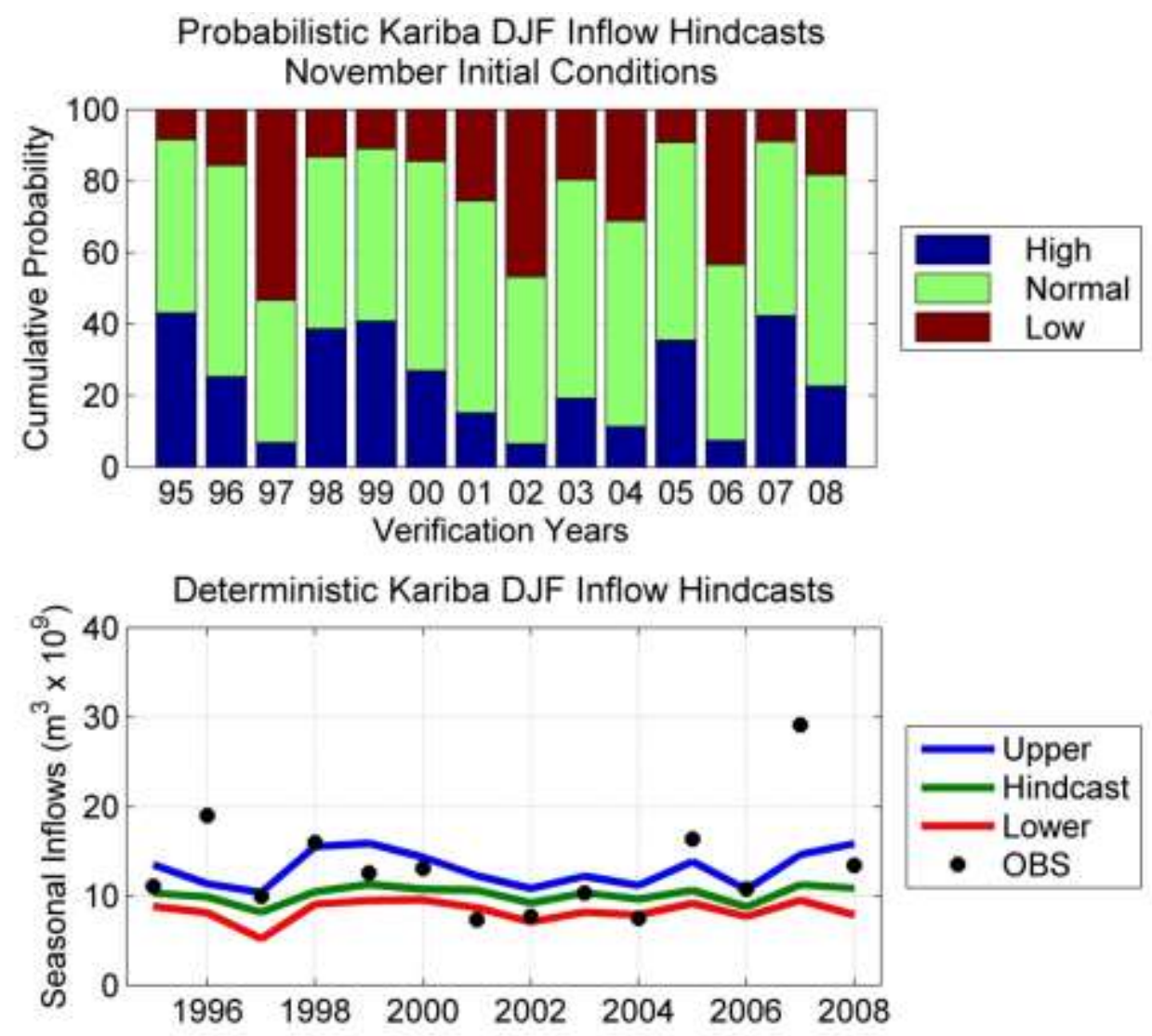



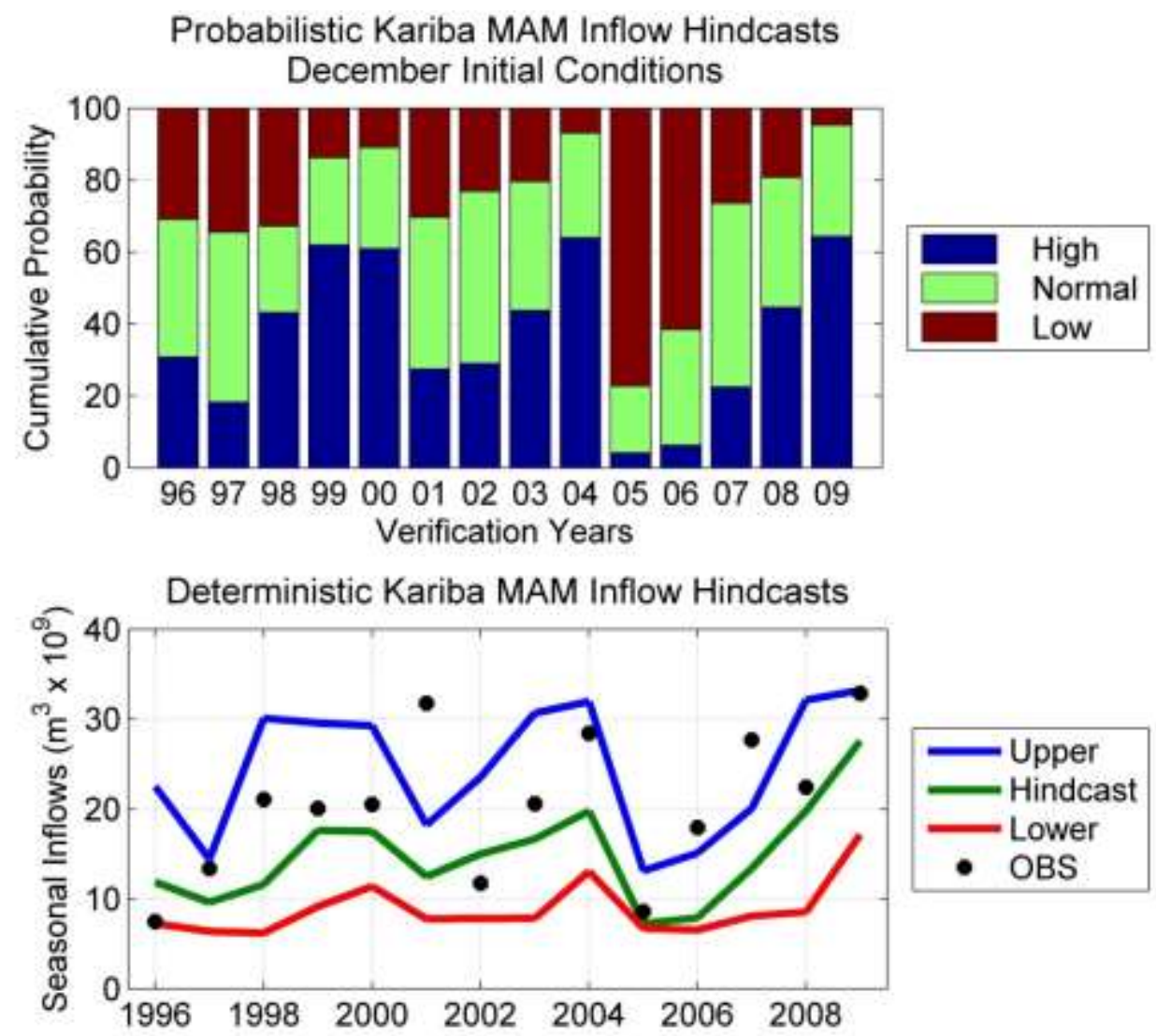

Figure $7 \mathrm{a}$ and $\mathrm{b}$. Probabilistic and determinisitic hindcasts of inflow totals for the DJF (a) and MAM (b) seasons. The categories of the probability hindcasts (top panels) are associated with the $25^{\text {th }}$ and 75 percentile thresholds of the climatological record, while the upper and lower ranges of the deterministic hindcasts (bottom panels) represent 1-standard deviations of the hindcasts.

\section{Independent Case study: The flood season of 2010/11}

This research was to a large extent motivated by the flooding season of 2010/11 when persistent summer rainfall over the Zambezi River Basin catchment area resulted in high water levels of Lake Kariba. Opening of the spillway gates resulted in rising water levels and increased flooding further downstream. The resulting flooding downstream resulted in loss of life and property. A skilful forecast could have been useful to Lake Kariba managers who needed to plan months ahead of the rainy season, consequently leading to reduced losses suffered during the actual flooding season. Owing to this extreme event that caused severe flooding over the catchment and associated high flows into the dam, we will attempt to next find out if the CGCM-based prediction system could have been able to issue a warning of the observed flooding several months ahead of time. Figure 8 a and $\mathrm{b}$, shows the DJF (onset) and MAM (main season) inflow probabilistic forecasts and their corresponding deterministic forecasts. The latter also shows the $25^{\text {th }}$ and $75^{\text {th }}$ percentile values defining respectively the low and high inflow thresholds for each season. Here one can see the predicted high probabilities for DJF inflow across all presented lead-times, and the enhanced probability MAM high inflow forecast at 3- and at 4-month leads. These 2010/11 forecasts provide evidence that the CGCM-based forecast system introduced here would have been able to predict with high confidence well ahead of time for extremely high flows to occur during the inflow onset season, but was less successful in predicting high flows during the peak season since enhanced probabilities of high inflows are only found for longer lead-times. Notwithstanding, these forecasts may have been useful to Lake Kariba managers who needed to plan months ahead of the rainy season, consequently leading to reduced losses suffered during the actual flooding season. 

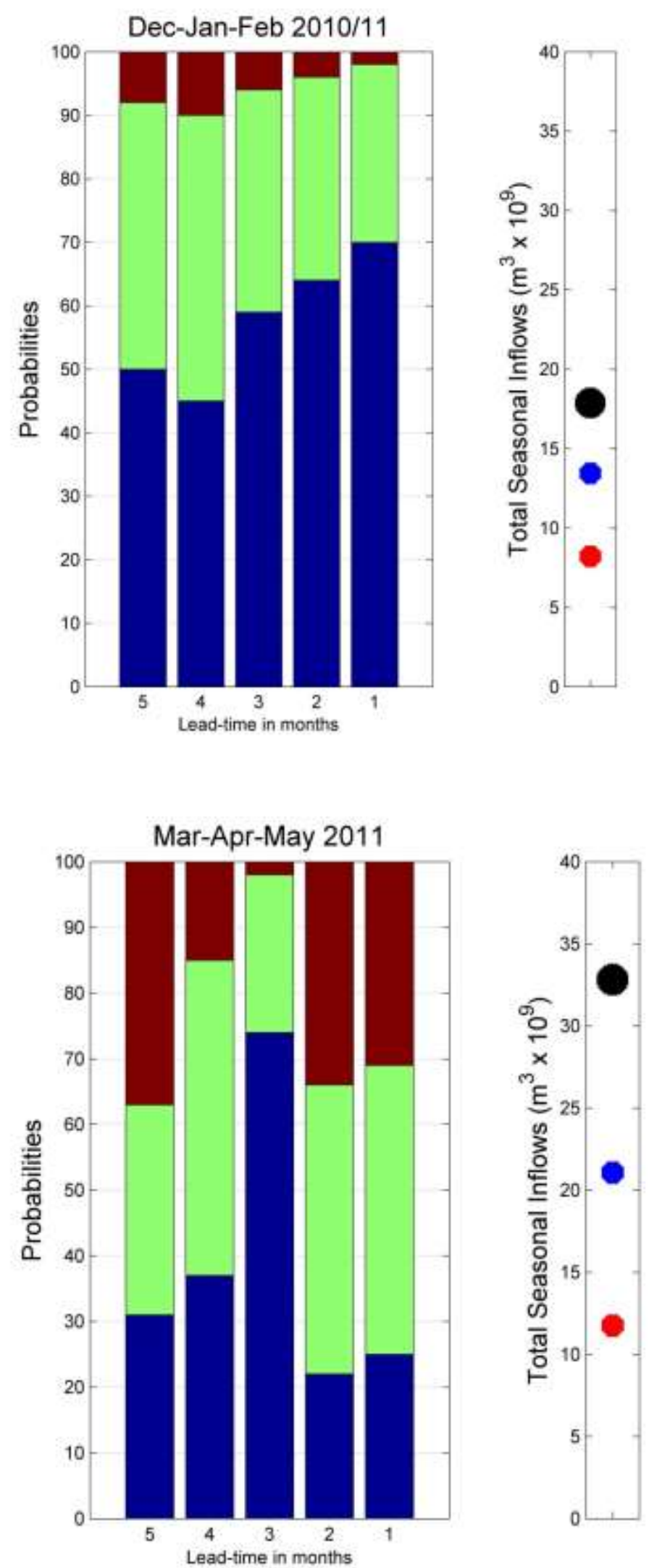

Figure8 a and b. DJF (onset) and MAM (peak) inflow forecasts for the 2010/11 season, made at lead-times from 1 to 5 months. The bars represent probabilities predicted for three categories of above- (blue), near- (green) and below-normal (red) seasonal inflow. On the right of the probability bars, the below- (red dot) and above-normal (blue dot) thresholds are shown along with the actual observed inflows (black dot). 


\section{Conclusion and discussion}

Lake Kariba is one of the largest sources of hydro-electric power in southern Africa. In addition, the Lake's catchment area is dominated by various agricultural activities, tourist attraction, fisheries and wildlife. In this regards, the water management system of the reservoir is crucial and would benefit from getting long-lead forecasts of the expected flow volumes into the Lake. The study therefore aims to provide such forecasts of high or low inflows into the dam to occur and their associated uncertainties. Such a prediction system should be able to provide key information on coming flood risk seasons to different stakeholders involved with, for example, hydropower production and water uses. Moreover, predictions for inflows into Lake Kariba should help reservoir managers to improve decisions to be made at the start of the main inflow time of the year regarding the likelihood of high or low rain-fed inflows into the reservoir to occur.

Two prediction systems have been presented and rigorously tested in this study. The first was based on using the antecedent seasonal rainfall over the upper Zambezi as a predictor in a simple statistical approach. The second is a more sophisticated system that involves a hybrid physical-empirical model that uses predicted low-level atmospheric circulation generated by a state-of-the-art climate model as a predictor in a statistical model. It was discovered that the more sophisticated modelling system presented superior levels of skill over the simple statistical model. This hybrid model demonstrated the ability to predict seasonal onset of inflows (DJF), but more modest albeit useable skill levels were found for the peak inflows (MAM). The skill was calculated over an independent test period of 14 years by testing the models in a true representation of an operational forecasting environment. Forecasts skilful in terms of discrimination and reliability were also found to be associated with the best guidance for users (e.g. improved profits associated with skilful forecasts). The higher skill associated with DJF inflows may be attributed to the fact the austral mid-summer circulation is skilfully captured by most general circulation/climate models. This time of the year is also when tropical influences start to dominate the atmospheric behaviour over southern Africa.

Next it was shown what actual forecasts may look like for some of the lead-times considered here. For DJF a 1month lead-time and for MAM a 3-month lead-time set of forecasts were shown as both probabilistic and deterministic outcomes. Not only were good verification results found for these lead times, but such lead-times potentially enable decisions to be made regarding optimal dam management and operations before the end of the calendar year proceeding the main inflow period. The probabilistic forecasts show the likelihood of inflows being below (above) the $25^{\text {th }}\left(75^{\text {th }}\right)$ percentile of the climatological record (in other words, extremes), while the deterministic forecasts are shown as inflow volumes $\left(\mathrm{m}^{3} \times 10^{9}\right)$ with accompanying forecast limits. Both types of forecasts may have to be assimilated into appropriate decision support systems in order to determine their relative value for dam management.

The DJF high probability forecasts for high (low) inflows are usually associated with La Niña (El Niño) years. For examples, the five highest probability forecasts for high inflows are associated with the La Niña seasons of 1995/96, 1998/99, 1999/2000, 2005/06 and 2007/08, while the four highest probability forecast years for low inflows during the 1997/98, 2002/03, 2004/5 and 2006/07 are associated with El Niño years. For the MAM forecasts presented, there is a good agreement between some of the high-probability forecast seasons (for both high and low volume inflows) and the deterministic estimates. For example, with increased seasonal flows towards 1999 and 2000, from 2002 to 2004, and from 2005 towards 2009, the forecast probabilities increased in accordance with the deterministic forecast ranges. Regarding the observed and predicted flows and their association with ENSO, this link seem to be weaker as was found for DJF - low inflows during the $1996 \mathrm{La}$ Niña and high inflows during the 2007 El Niño.

This research was to a large extent motivated by the flooding season of 2010/11 when persistent summer rainfall in the Zambezi River Basin catchment area resulted in high water levels of Lake Kariba. Opening of the spillway gates resulted in rising water levels and increased flooding further downstream of Lake Kariba as well as jeopardizing effective reservoir management at Cahora Bassa downstream in Mozambique. Moreover, the resulting flooding downstream resulted in loss of life and property. The hybrid prediction system was also used to predict inflows during this season, and it was found that in particular for the DJF (onset) season high probabilities and above-normal deterministic outcomes were predicted, thus providing evidence that the 
abovementioned societal and management problems could have at least been to some extent alleviated had these long-lead forecasts of extreme flooding been released in late 2010. The paper has demonstrated that the hybrid prediction system has the potential to produce forecasts that may benefit decision making under certain conditions (i.e. onset of inflows, ENSO seasons, etc.) and therefore has demonstrated the value of applying seasonal forecasts of skill to a particular application.

\section{ACKNOWLEDGEMENTS}

This material is based upon work fully supported financially by the Applied Center for Climate and Earth Systems Science (ACCESS). The authors would like to thank Zambezi River Authority (ZRA) for the use of their data accessed through their Office.

\section{References}

Balek, J, 1971. Water balance of the Zambezi Basin. Technical Report15. Lusaka, Zambia: National Council for Scientific Research.

Barnston AG, He Y, Glantz MH, 1999. Predictive skill of statistical and dynamical climate models in SST forecasts during the 1997-98 El Nĩno episodes and the 1998 La Niña onset. Bull. Am. Meteorol. Soc, 80 217244.

Barnston AG, Kumar A, Goddard L, Hoerling M P, 2004. Improving seasonal prediction practices through attribution of climate variability. Bull. Amer. Meteor. So., 86: 59-72.

Brown JD, Demargne J, Seo D-J, Liu Y, 2010. The Ensemble Verification System (EVS): A software tool for verifying ensemble forecasts of hydro meteorological and hydrologic variables at discrete locations. Environmental Modelling \& Software, 25: 854-872.

Cane MA, Eshel G and Buckland RW, 1994. Forecasting Zimbabwean maize yield using eastern Pacific sea surface temperatures. Nature, 370: 204-206.

Chen S-T, Yu P-S, 2007: Real-time probabilistic forecasting of flood stages. Journal of Hydrology, 340: 63- 77.

Chidanti-Malunga J, 2011. Adaptive strategies to climate change in Southern Malawi. Physics and Chemistry of the Earth, 36: 1043-1046.

Chiew FHS, McMahon TA, 2002. Global ENSO-streamflow teleconnection, streamflow forecasting and interannual variability. Hydrol. Sci., 47: 505-522.

Cloke HL, Pappenberger F, 2009. Ensemble flood forecasting: A review. Journal of Hydrology, 375: 613-626.

David RI, Kazimierz A S, 2004: The operation of Lake Kariba: A Bayesian Analysis. Journal of Multi-Criteria Decision Analysis, 4: 203-222. DOI: 10.1002/mcda.4020040402.

Dettinger MD, Cayan DR, McCabe GJ, Marengo JA, 2000. Multiscale streamflow variability associated with El Nino/ Southern oscillation. In: Diaz, H.F., Markgraf, V. (Eds.), El Nino and the Southern Oscillation: Multiscale Variability and Global Regional Impacts, Cambridge University Press, Cambridge, pp. 113-147.

DeWitt D G, 2005. Retrospective forecasts of interannual sea surface temperature anomalies from 1982 to present using a directly coupled atmosphere-ocean general circulation model. Mon. Wea. Rev., 133: 2972-2995. doi: http://dx.doi.org/10.1175/MWR-D-11-00177.1 
Ebert EE, McBride JL, 2000. Verification of precipitation in weather systems: determination of systematic errors. Journal of Hydrology, 239: 179-202.

Faber BA, Stedinger J R., 2001. Reservoir Optimization using sampling SDP with ensemble streamflow prediction (ESP) forecasts. Journal of Hydrology, 249: 113-133.

Ghosh S, Mujumdar PP, 2008. Statistical downscaling of GCM simulations to streamflow using relevance vector machine. Advances in Water Resources, 31: 132-146.

Glahn H, Lowry R, 1972. The use of model output statistics (MOS) in objective weather forecasting. J. Appl. Meteor., 11: 1203-1211.

Goetz JN, Guthrie RH, Brenning A, 2011.Integrating physical and empirical landslide susceptibility models using generalized additive models. Geomorphology, 129: 376-386.

Hagedorn R Smith LA, 2008. Communicating the value of probabilistic forecasts with weather roulette. Meteorol. Appl. 1-13. DOI: 10.1002/met.

Hamill TM, 1997. Reliability diagrams for multicategory probabilistic forecasts. Wea. Forecasting, 12: 736741.

Hamlet AF, Huppert D, Lettenmaier DP, 2002. Economic value of long-lead streamflow forecasts for Columbia River hydropower, Journal of Water Resources Planning and Management, 128: 91-101.

Hansen JW, 2002. Applying seasonal climate prediction to agricultural production (preface). Agricultural Systems, 74: 305-307.

Harris I, Jones PD, Osborn TJ, Lister DH, 2013. Updated high-resolution grids of monthly climatic observations. Int. J. Climatol., 34: 623-642, Doi: 10.1002/joc.3711).

Hastenrath S, Greischar L, van Heerden J, 1995. Prediction of summer rainfall over South Africa. J. Clim. 8: 1511-1518.

Jolliffe IT, Stephenson DB, 2012. Forecast Verification: A Guide in Atmospheric Science. John Wiley \& Sons Ltd, The Atrium, Southern Gate, Chichester, West Sussex PO19 8SQ, England. ISBN 0-471-49759-2.

Jury MR, Makarau A, 1996. Predictability of Zimbabwe Summer Rainfall. Int J. Climatol., 17:1421-1432.

Kashid SS, Ghosh S, Maity R, 2010. Streamflow prediction using multi-site rainfall obtained from hydroclimatic teleconnection. Journal of Hydrology, 395: 23-38.

Krzysztofowicz R, 1999. Bayesian theory of probabilistic forecasting via deterministic hydrologic model. Water Resources Research, 35: 2739-2750.

Krzysztofowicz R, 2001. The case of probabilistic forecasting in hydrology. Journal of Hydrology, 249: 2-9.

Landman WA, 2014. How the International Research Institute for Climate and Society has contributed towards seasonal climate forecast modelling and operations in South Africa. Earth Perspectives, 1:22, DOI: $10.1186 / 2194-6434-1-22$.

Landman WA, 2001. Forecasts or near-global sea surface temperatures using canonical correlation analysis. $J$. Climate, 14: 3819-3833.

Landman WA, and 4 co-authors, 2012. Seasonal rainfall prediction skill over South Africa: One- versus twotiered forecasting systems. Weather and Forecasting, 27: 489-501. 
Landman WA, Beraki A, 2012. Multi-model forecast skill formid-summer rainfall over southern Africa. Int. $J$. Climatol., 32: 303-314.

Landman WA, Goddard L, 2002. Statistical recalibration of GCM forecast over southern Africa using model output statistics. J. Climate, 15: 2038-2055.

Lazenby MJ, Landman WA, Garland RM, DeWitt DG, 2014. Seasonal temperature prediction skill over Southern Africa and human health. Meteorological Applications Meteorol. Appl. (2014).

Lessmann S Sung M-C, Johnson J EV, Ma T, 2012. A new methodology for generating and combining statistical forecasting models to enhance competitive event prediction. European Journal of Operational Research, 218: 163-174.

Madeiros-Braga ACF, Da Silva RM, Guimarães S C A, Stam A, Salewicz K A, Aronson J E, 1998. An interactive reservoir management system for Lake Kariba. European Journal of Operational Research IO7 119136.

Maier HR, Dandy GC, 2000.Neural networks for the prediction and forecasting of water resources variables: a review of modelling issues and applications. Environmental Modelling \& Software, 15: 101-124.

Makarau A, Jury MR, 1997. Predictability of Zimbabwe summer rainfall. Int. J. Climatol, 17: 1421-1432.

Marco B, Fausto T, Alberto P, 2010: Development and testing of a physically based, three-dimensional model of surface and subsurface hydrology Adv. Water Resour, 33: 106-122.

Mason SJ, Graham NE, 2002. Areas beneath the relative operating characteristics (ROC) and levels (ROL) curves: Statistical significance and interpretation. Quart. J. Roy. Meteor. Soc., 128: 2145-2166.

McMahon TA, Finlayson BL, Haines AT, Srikanthan R, 1992. Global Runoff-Continental Comparisons of Annual Flows and Peak Discharges.Catena: Cremlingen-Destedt, Germany. P.166.

Mesinger F, 1996. Improvements in quantitative precipitation forecasts with the eta regional model at the National Centers for Environmental Prediction: the 48-km upgrade. Bull. Am. Meterol. Soc, 77: 2637-2649.

Mitchell TD, Jones PD, 2005. An improved method of constructing a database of monthly climate observations and associated high-resolution grids. International Journal of Climatology, 25: 693-712.

Muchuru S, Landman WA, DeWitt D, Lötter D, 2014. Seasonal rainfall predictability over the Lake Kariba catchment area. Water SA, 40: 461-470 http://dx.doi.org/10.4314/wsa.v40i3.9

Muluye GY, 2011. Implications of medium-range numerical weather model output in hydrologic applications: Assessment of skill and economic value. Journal of Hydrology, 400: 448-464.

Ncube SP, Makurira H, Kaseke E, Mhizha A, 2011.Reservoir operation under variable climate: Case of Rozva Dam, Zimbabwe. Physics and Chemistry of the Earth, 36: 1112-1119.

Ndiaye O Ward MN, Thiaw WM, 2011. Predictability of seasonal Sahel rainfall using GCMs and lead-time improvements through the use of a coupled model. J. Climate, 24: 1931-1949.

Opitz-Stapleton S, Gangopadhyay S, Rajagopalan B, 2007. Generating streamflow forecasts for the Yakima River Basin using large-scale climate predictors. Journal of Hydrology, 341: 131- 143.

Pacanowski RC, Griffies SM, 1998. MOM3.0 Manual. A Technical Guide to MOM4 GFDL Ocean Group Technical Report NO. 5. NOAA/ Geophysical Fluid Dynamics Laboratory. Princeton, NJ; 608.

Palmer T N and Coauthors, 2004. Development of a European Multimodel Ensemble System for Seasonal-toInterannual Prediction (DEMETER). Bull. Amer. Meteor. Soc, 85: 853-872. 
Palmer TN, Anderson DLT, 1993. Scientific assessment of the prospects for seasonal forecasting a European perspective. ECMWF Tech. Report No. 70, Reading, UK.

Partington D, Brunner P, Simmons CT, 2012. Evaluation of outputs from automated baseflow separation methods against simulated baseflow from a physically based, surface water-groundwater flow model. J. Hydrol, 458-459: 28-39.

Pedersen CB, Madsen H, Skotner C, 2007. Real-Time Optimization of Dam Releases Using Multiple Objectives. Application to the Orange-Fish-Sundays River Basin, South Africa; 13th SANCIAHS Symposium, 6-7 September, 2007, Cape Town, South Africa.

Raje D, Mujumdar PP, 2010: Reservoir performance under uncertainty in hydrologic impacts of climate change. Advances in Water Resources, 33: 312-326.

Refsgaard JC, Knudsen J, 1996. Operational validation and intercomparison of different types of hydrological models. Water Resources Research, 32: 2189-2202.

Richardson DS. 2000. Skill and economic value of the ECMWF ensemble prediction system. Quarterly Journal of the Royal Meteorological Society, 126: 649-668.

Robertson AW, Dian-Hua Q, Michael KT, 2012. Downscaling of Seasonal Rainfall over the Philippines: Dynamical versus Statistical Approaches. Mon. Wea. Re., 140: 1204-1218.

Roeckner E, and Coauthors, 1996. Regional climate simulation with a high resolution GCM: Surface hydrology. Climate Dyn, 12, 755-774

Roulston MS, Smith LA, 2003. Combining dynamical and statistical ensembles. Tellus Series A-Dynamic Meteorology and Oceanography, 55: 16-30.

Schaake J and Coauthors, 2010. Summary of recommendations of the first workshop on Postprocessing and Downscaling Atmospheric Forecasts for Hydrologic Applications held at Météo-France, Toulouse, France, 1518 June 2009. Atmos. Sci. Lett, 11: 59-63.

Schaake JT, Hamill M, Buizza R, 2007b. Hepex: The Hydrological Ensemble Prediction Experiment. Bull. Amer. Meteor. Soc, 88: 1541-1547.

Sharma T C, Nyumbu I L, 1985. Some hydrologic characteristics of the Upper Zambezi Basin. Pages 29-43 in.L. Handlos and G.W. Howard, eds. Development Prospects for the Zambezi Valley in Zambia. Lusaka: Kafue Basin Research Committee of the University of Zambia.

Shongwe ME, Landman W A., Mason SJ, 2006. Performance of recalibration systems for GCM forecasts for southern Africa. Int. J. Climatol, 26: 1567-1585.

Solomon SD. Qin M, Manning Z, Chen M, Marquis K, Averyt B, Tignor M, Miller H L. (eds.) 2007. Regional Climate Projections. In: Climate Change 2007: The Physical Science Basis. Contribution of Working Group 1 to the Fourth Assessment Report of the Intergovernmental Panel on Climate Change Cambridge University Press, Cambridge, United Kingdom and New York, NY, USA.

Thielen J, Schaake J, Hartman R, Buizza R, 2008. Aims, challenges and progress of the Hydrological Ensemble Prediction Experiment (HEPEX) following the third HEPEX workshop held in Stresa 27 to 29 June 2007. Atmos. Sci. Lett, 9: 29-35.

Tisseuil C, Vrac M, Lek S, Wade AJ, 2010. Statistical downscaling of river flows. Journal of Hydrology, 385: 279-291. 
Tong STY, Sun Y, Ranatunga T, He J, and Yang YJ, 2012. Predicting plausible impacts of sets of climate and land use change scenarios on water resources. Applied Geography, 32: 477-489.

Troccoli A, Harrison M, Anderson DLT, Mason SJ. 2008: Seasonal Climate: Forecasting and Managing Risk. NATO Science Series on Earth and Environmental Sciences, 82: Springer, 467 pp.

Tumbare MJ, 2000. Management of River Basin and Dams: The Zambezi River Basin, AA Balkema, Rotterdam/Brookfields.

Tumbare MJ, 2000.Mitigating floods in Southern Africa, in 1st WARFSA/WaterNet Symposium: sustainable use of water resources, pp. 1-8, Maputo, Mozambique.

Wei CC, Hsu, NS, 2005. A real-time optimization model for flood control. In: 2005 AGU Fall Meeting, San Francisco, CA.

Welsh WD, Vaze J, Dutta D, Rassam D, Rahman JM, Jolly ID, Wallbrink P, Podger GM, Bethune M, Hardy MJ, Teng J, Lerat J, 2012. An integrated modelling framework for regulated river systems. Environmental Modelling \& Software. http://dx.doi.org/10.1016/j.envsoft.2012.02.022.

Wilby RL, Dawson CW, Barrow EM, 2002. SDSM - a decision support tool for the assessment of regional climate change impacts. Environ. Model. Software, 17: 147-159.

Wilks D, 2006a. Statistical Methods in the Atmospheric Sciences, 2nd edn. Academic Press: New York, 2nd edition, 627, see chapter 7 (255-332).

Wilks, D S, 2006.Statistical Methods in the Atmospheric Sciences. 2nd ed. Academic Press, 627 pp.

Wilks, D S, 2011. Statistical Methods in the Atmospheric Sciences.3nd ed. International geophysics series, Vol.100.

Ziervogel G, Bithell M, Washington R, Downing T, 2005. Agent-based social simulation: a method for assessing the impact of seasonal climate forecast applications among smallholder farmers. Agricultural Systems, 83: $1-26$.

ZRA, 2005. Report on the Standard Operating Procedures (SOP) for Zambezi River Authority on Kariba Dam and Reservoir, November, 2005 